\title{
EI tiempo del delito en las ciudades castellanas a fines de la Edad Media
}

\author{
The Time for Crime in Castilian Cities at the End of the \\ Middle Ages
}

\author{
Ezequiel BORGOGNONI \\ Universidad de Buenos Aires, Argentina \\ eborgognoni@filo.uba.ar
}

\begin{abstract}
RESUMEN
Cuando el cielo se oscurecía y las campanas de las iglesias anunciaban el inicio de la noche en las distintas ciudades medievales del reino de Castilla, los delincuentes encontraban un terreno fértil para cometer diferentes tipos de delitos amparados por el anonimato de las tinieblas. Inmediatamente, las autoridades citadinas tomaron medidas con la intención de establecer un control de las actividades nocturnas. En el presente artículo, analizaremos las vinculaciones entre el mundo del delito y la noche para finalmente poner de manifiesto las distintas herramientas instrumentadas desde los municipios con el objetivo de lograr una siempre incompleta "domesticación" de la nocturnidad.
\end{abstract}

Palabras clave: Delincuencia, Mundo urbano, Castilla, Noche, Vigilancia nocturna.

\begin{abstract}
When the sky darkened and church bells announced night had fallen in different cities of the medieval kingdom of Castile, criminals found fertile ground for committing various types of crime sheltered by the anonymity of darkness. Immediately, the city authorities took all the necessary measures to control life at night. In this paper, we will analyze the links between the criminal world and the night to finally reveal the various means utilized by municipalities in order to achieve if only a partial "domestication" of life at night.
\end{abstract}

Key words: Crime, Cities, Castile, Night, Night Surveillance.

Sumario: 1. El tema y las fuentes. 2. El tiempo del delito. Homicidas, ladrones, impostores y malhechores en las ciudades castellanas. 2.1. El tiempo de matar. 2.2. El tiempo de robar. 2.3. El tiempo de timar. 2.4. El tiempo de atacar. 3. Las leyes de la noche: intentos de domesticación de la nocturnidad en Castilla. 3.1. Los municipios y su potestad normativa para la regulación de la vida nocturna citadina. 3.2. Los límites a la circulación nocturna, el toque de queda y la portación de lumbre encendida. 3.3. El control del uso de las armas. 3.4. El poder de los alguaciles. 3.5 Las rondas nocturnas. 3.6 Las restricciones al ingreso de forasteros. 3.7 La vigilancia nocturna desde las murallas. 4. Algunas reflexiones finales. 


\section{EL TEMA Y LAS FUENTES}

Durante la Edad Media, la llegada de la noche propiciaba la salida de los malhechores, los marginados y los alborotadores en las distintas ciudades del occidente europeo. Los historiadores que se han ocupado de esta cuestión han centrado sus estudios en los casos inglés ${ }^{1}$, francés ${ }^{2}$ e italiano ${ }^{3}$. De momento no existe ninguna obra de referencia que se aboque con exclusividad al estudio de los vínculos entre la nocturnidad y el mundo del delito en el espacio castellano. Por tal motivo, nos proponemos analizar la relación entre delito y horas nocturnas en Castilla a fines de la Edad Media. ¿Era la noche el momento más propicio para cometer un delito? ¿Cuáles eran los delitos más habituales que tenían lugar en el mundo urbano castellano al amparo de las tinieblas? ¿Qué tipo de respuestas brindaron las autoridades? ¿Qué ponían de manifiesto las fuentes legislativas al respecto?

Antes de aproximarnos al estudio de las relaciones entre el universo del delito y la nocturnidad en el caso castellano es importante precisar algunas cuestiones en relación a las fuentes. En Castilla no encontramos ninguna fuente que nos permita arribar a conclusiones acabadas sobre cuál era la hora más proclive para el delito. Los especialistas para el caso inglés tienen una ventaja de la cual carecemos los estudiosos para el ámbito hispánico puesto que en Inglaterra se conserva un tipo de fuente que brinda una enorme cantidad de información en relación al momento del día en el que se producía un crimen. Nos referimos a los Coroner's Rolls, un tipo de registro de las actas de las investigaciones que se realizaban sobre los cuerpos de los fallecidos en forma violenta o en circunstancias sospechosas. En los Coroner's Rolls se especifican el lugar, el día y la hora del fallecimiento junto a los motivos y una cantidad importante de datos que eran requeridos por los jueces. En Castilla, el propio carácter de las fuentes no nos permite realizar conclusiones taxativas que postulen la complementariedad del vínculo delito-noche. No obstante, esta insuficiencia cuantitativa derivada de la propia naturaleza documental no es motivo suficiente para justificar el desinterés de la historiografía y tampoco invalida la realización de los estudios de enorme interés cualitativo. Aunque el presente artículo no permita elaborar un registro estadístico que ponga de manifiesto la relación entre el delito y la noche, sin embargo aportará datos interesantes sobre los comportamientos y mentalidades de los hombres del medievo.

${ }^{1}$ Cfr. Bárbara Hanawalt, "Violent Death in Fourteenth and early Fifteenth-century England", Journal of Comparative Studies in Society and History, 18 (1976).

${ }^{2}$ Cfr. Robert Muchembled, La violence au village (XVe-XVIIe siècles), Bruxelles, Brepols, 1989; Claude GAUVARD, De grace especial: crime, état et societé en France à la fin du moyen age, Paris, Publications de la Sorbonne, 1991; Jean Verdon, Night in the Middle Ages, Notre Dame-Indiana, University of Notre Dame Press, 2002.

${ }^{3}$ Cfr. Elisabeth Crouzet-PAVAN, "Recherches sur la Nuit vénitienne a la fin du Moyen Age", Journal of Medieval History, 7 (1981). Al inicio de la década de 1990 Mario Sbriccoli reunió a un grupo de especialistas en la materia que se abocaron al estudio de la nocturnidad italiana entre la baja Edad Media y los albores de la modernidad; la labor mancomunada arrojó como resultado la publicación de una obra de consulta obligada. Véase Mario Sbriccoli (ed.) La Notte. Ordine, sicurezza e disciplinamento in età moderna, Firenze, Ponte alle Grazie, 1991. 
Juan Miguel Mendoza Garrido explica con claridad el problema que presenta la documentación castellana; y por esto nos encontramos imposibilitados de establecer un patrón temporal dominante en los homicidios que se cometían en Castilla-La Mancha a fines de la Edad Media:

“...siento tener que decir que, a partir de las fuentes disponibles, es muy poco, casi nada, lo que puede averiguarse sobre este aspecto para Castilla-La Mancha. Desde un punto de vista estadístico no podría afirmarse nada, ya que del gran número de homicidios que se recogen en el Registro General del Sello, sabemos con cierta aproximación la hora y día en que ocurrieron los hechos en apenas media docena de casos. Otro tanto sucede en las cuentas de la Hermandad de Ciudad Real, que sólo hacen referencia a la hora del homicidio en tres ocasiones, mientras que nunca se menciona este dato en los escasos homicidios registrados en la Chancillería"4.

Ricardo Córdoba de la Llave afirma que "aunque en la documentación castellana [la noche] es un dato que apenas se proporciona y que sólo aparece en contadísimas ocasiones, cuando lo hace se alude siempre a la nocturnidad o al período de sombras del anochecer como momento en que ocurrió el delito"s. Algunos casos que aparecen en nuestra documentación nos permiten advertir el nivel de violencia nocturno en las ciudades castellanas durante la baja Edad Media. La noche es un tiempo peligroso puesto que está poblada de asesinos, ladrones, impostores y malhechores.

\section{EL TIEMPO DEL DELITO. HOMICIDAS, LADRONES, IMPOSTORES Y MALHECHORES EN LAS CIUDADES CASTELLANAS}

\subsection{EL TIEMPO DE MATAR}

Los asesinos encontraban un terreno fértil en la oscuridad de la noche que los amparaba como cómplices en sus delitos. Los especialistas en la materia afirman que "los asesinos, potenciales o consumados, que desfilan por nuestras fuentes, a juzgar por las declaraciones de las partes acusadoras, ofrecen retratos de personajes que parecen vivir al acecho y agazapados, que andan bien pertrechados de armas, que prefieren la noche y que apuntan con bastante precisión y rapidez"6. En 1480 Juan de Torres apuñalaba en la cabeza a Alfonso de Padilla en Jerez a la ora del abe maría que podía ser una ora poco más o menos después de puesto el sol. El crimen tuvo lugar en una calijuela que está çerca de la calle de francos ${ }^{7}$. Si bien este

${ }^{4}$ Juan Miguel Mendoza Garrido, Delincuencia y represión en la Castilla bajomedieval: los territorios castellano-manchegos, Granada, Grupo Editorial Universitario, 1999, p. 167.

${ }^{5}$ Ricardo Córdoba de la llave, El homicidio en Andalucía a fines de la Edad Media, Granada, Universidad de Granada, 2007, p. 46.

${ }^{6}$ Juan Miguel Mendoza Garrido; Clara Almagro Vidal; María Ángeles Martín Romera; Luis Rafael Villegas Díaz, "Delincuencia y justicia en la Chancillería de Ciudad Real y Granada (14951510). Primera Parte. Estudio", Clio \& Crimen, 4 (2007), p. 420.

7 1480.10.21, Archivo General de Simancas, Registro General del Sello (AGS y RGS, en lo sucesivo), f. 207. 
artículo analiza el ritmo temporal del delito, es importante resaltar que la criminalidad tenía asimismo sus espacios favoritos por excelencia en zonas marginales urbanas, despoblados y caminos. En 1485 Martín de Tamayo y su mujer, vecinos de Santaella, fueron agredidos por su cuñado y otro hombre en el interior de su casa una noche a dos horas de la noche Juan, criado de Diego de Úbeda, estando en la puerta de su casa en el barrio de San Pedro a las tres horas de la noche. ${ }^{9}$ En el mismo año pero en la villa de Baena el vecino Bartolomé Correero peticionaba para que se aprisionase a los malhechores que habían asesinado a su hijo Diego Martínez de 17 años mientras una noche trataba de poner paz en una pelea que presención ${ }^{10}$.

Los asesinatos nocturnos en el ámbito familiar en ocasiones se vinculaban al adulterio. Se conserva una petición santafesina del año 1492 presentada por Marina Sánchez en la que se pide que se cumpla una sentencia de muerte dictada contra su yerno Alfonso de Carmona que había tratado de envenenar y acuchillar a su esposa María Sánchez puesto que creía que su cónyuge le había cometido adulterio. El intento de homicidio había tenido lugar durante la noche mientras la víctima se encontraba descansando.

Don Fernando e doña Ysabel [...] Sepades que marina sánches, vesyna de la çibdad de Ubeda, nos fizo Relaçión eçetera diziendo que alfonso de carmona está casado legítimamente segund manda la madre santa yglesia con maría sánches, su fija, e estando asy casada dis que por ynduzimyento de una catalina de baldyvia que le quería mal le dixo que la dicha su muger le cometya Adulteryo, non seyendo ello asy, e syn se ynformar dello nyn saber otra cosa alguna salvo lo que la dicha catalina de baldyvia con dañada yntençión le dixo, dis que el dicho alfonso de carmona, estando una noche acostado con la dicha su muger e estando ella dormyendo le echó en la boca çiertos polvos de Rejalgar e le dyó treze o catorze puñaladas de que estovo a punto de morir, sobre lo qual diz que fue acusado por ante las justiçias de la dicha çibdad fasta que fue condenado a pena de muerte, e que a cabsa que el dicho alfonso de carmona anduvo absentado nunca ha podydo ser executada la dicha sentençya $[. . .]^{11}$

El 17 de noviembre de 1492 la mujer del jurado Juan de Cuadros pide al Concejo de Olmedo que se ejecute una sentencia de muerte dictada contra Rodrigo Álvarez, que había estado casado con su sobrina Beatriz Fernández. Esta última había sido asesinada durante la noche por su marido por sospechas infundadas de adulterio.

Sepades que la muger del jurado Juan de quadros, vezina de la dicha çibdad de sevilla nos enbió faser Relaçión por su petiçión que en el nuestro qonsejo fue presentada diziendo que seyendo beatris fernándes, su sobrina, fija de su hermana casada por legítimo matrimonyo segund manda la santa madre yglesia con don Rodrigo Alvares, vesyno de la dicha çibdad de sevylla, e el dicho Rodrigo Alvares syn cabsa nyn Rasón alguna legítima e syn tener sospecha que la dicha su muger le ovyese

\footnotetext{
${ }^{8}$ 1485.02.16, AGS, RGS, f. 150.

9 1492. 04. 10. AGS, RGS, ff. 62 y 95.

10 1492.03.13. AGS, RGS, f. 352.

11 1492.04.04. AGS, RGS, f. 419.
} 
ofendido, estando acostado una noche con ella en la cama con sobra de crueldad e demasyada codiçia, pospuesto el themor de dyos y de nuestra Justiçia y estando la dicha beatris fernándes preñada de seys meses del dicho Rodrygo, su marido, dis que dyo de puñaladas e la mató estando ella dormyendo syn culpa alguna, e dis que non contento de lo susodicho le rasgó los braços por la sacar y tomar çiertas manyllas que en ellas tenya, y asy mysmo dis que le llevó otras munchas cosas que la dicha beatris fernándes tenya y heran suyas, y todas las otras cosas que le avya dado y las cosas que le fueron dadas en casamyento con ella, fuyó y se absentó despues de perpetrados e cometidos los dichos delitos $[\ldots]^{12}$

En este caso el principal agravante que encubrió la muerte de Beatriz Fernández estuvo dado por el embarazo que el asesino interrumpió. Rodrigo Álvarez fue condenado a pena de muerte pero inmediatamente huyó hacia la villa de Montilla. Las autoridades de Olmedo solicitaron la captura del reo.

No debemos suponer que los sectores privilegiados eran ajenos a la violencia doméstica perpetrada bajo el manto de la noche. Pedro Carrillo de Huete relata un suceso acaecido en 1436 en el que una dama de la nobleza fue mandada a asesinar por su marido el conde por haber cometido adulterio.

Estando el rey en la su ciudad de Toledo, a trece dias de septiembre, viniéronse nuevas en cómo el conde de Castro, don Diego Gómez de Sandoval, envío desde Aragón, donde estaba desterrado a don Diego de Sadoval, su sobrino, e a un bachiller suyo con fasta veynte roçines a Villafrechos, lugar suyo donde estaba la condesa su muger en un monasterio de monjas. E llamaron a la puerta deziendo que el conde venía allí, e entraron dentro en la cámara onde la condesa estava, de noche, e afogáronla. La raçon porque el conde mandó fazer esto fue porque estando él ausente usó mal de su persona ${ }^{13}$.

Para un hombre de la baja Edad Media ser engañado por su mujer constituía un ataque directo a su honra y este agravio sólo podía lavarse con la muerte de la mujer adúltera. La mujer adúltera ha cometido un delito en sentido doble puesto que el adulterio femenino es un pecado grave a la vez que un delito jurídico severo ${ }^{14}$. Mendoza Garrido sostiene que en los casos de adulterio femenino, el marido generalmente optaba por dar muerte a la mujer previa cualquier actuación judicial. Acto seguido, el homicida debía justificar los hechos, aportar pruebas del adulterio cometido por la mujer, contar con el perdón de los parientes de la adúltera y recurrir a los reyes para obtener el perdón definitivo. Hemos visto que en los casos analizados los esposos no obtienen el perdón de los parientes de la víctima; por tal motivo, el caso deriva en una instancia judicial. Este comportamiento masculino era bastante frecuente a fines

12 1492.11.17. AGS, RGS, f. 222.

13 Pedro Carrillo de Huete, Crónica del Halconero de Juan II, ed. Juan de Mata Carriazo, Madrid, Espasa-Calpe, 1946, p. 233. Verdon sostiene que la noche es el terreno propicio para el adulterio puesto que "lustful women took advantage of the absence of their husbands to deceive them" (Jean VERDON, op cit; p. 38).

${ }^{14}$ Ricardo Córdoba de la Llave, “Adulterio, sexo y violencia en la Castilla medieval”, Espacio, Tiempo y Forma, serie IV, Historia Moderna, t. 7 (1994), p. 157. 
de la Edad Media ${ }^{15}$. Asimismo el propio padre de la mujer adúltera es en reiteradas ocasiones el ejecutor de un crimen con carácter legítimo ${ }^{16}$.

Los casos hasta aquí presentados imposibilitan la configuración de un perfil social que de cuenta de los sectores más involucrados en los homicidios nocturnos. Tanto los agresores como sus víctimas pertenecían a distintos grupos sociales. Los crímenes envueltos en la oscuridad de la noche afectaban a todos por igual. En la sección del Registro General del Sello perteneciente al Archivo General de Simancas se conserva una petición presentada en el Consejo y fechada el 9 de agosto de 1479 en Trujillo. El denunciante Gonzalo Núñez de Écija pide que se ejecute una sentencia de muerte dictada contra Juan de Carmona quien había asesinado a su padre el bachiller Alfonso Núñez a pesar de que el acusado había servido en la villa de Jimena para ganar el privilegio de homiciano de dicha villa.

Gonçalo núñes, fijo del bachiller Alfonso núñez, fisyco, vesyno de sevylla. Para todas las justiçias, que vean una sentençya contra Juan de Carmona que fue en matar al bachyller, su padre, la esecuten en él no enbargante que aya servydo en Ximena, por quanto le non debe valer por lo matar yntervynyendo aleve e trayçión e muerte segura, estando en asechanças, de noche, saliendo el dicho bachiller del palaçio del Rey y de la Reyna ${ }^{17}$.

El documento anteriormente citado evidencia por lo menos dos cuestiones. En primer lugar, nos presenta el asesinato nocturno de un físico de la Corona cuando el mismo estaba saliendo del palacio de sus majestades. El hecho de que la víctima sea un físico y que este hecho se repita frecuentemente en la fuente no es fortuito. Los asesinatos afectan a todos por igual pero la propia condición "profesional" de la víctima acentúa el perjuicio del acto criminal. Por otra parte, la mención de la nocturnidad se incluye como un agravante judicial que da cuenta de la alevosía del acto.

\subsection{EL TIEMPO DE ROBAR}

Los robos nocturnos a casas, tiendas y personas eran bastantes frecuentes. Las actas que se han conservado de las reuniones del Cabildo de Jurados de Toledo ponen de manifiesto esta situación y hacen hincapié en que los propios vecinos deben unirse y tomar precauciones para prevenirse de la inseguridad. El 30 de marzo de 1482 los

${ }^{15}$ Juan Miguel Mendoza Garrido, op. cit; p. 178.

${ }^{16}$ Fallando el padre á su fija que fuese casada, faciendo adulterio con algunt home en su casa misma o en la de su yerno, puede matar a su fija et al varon que fallare con ella faciendo nemiga; pero non debe matar al uno e dexar al otro; et si lo ficiere cae en pena...(Partida VII, Título XVII, Ley XIV). En materia bibliográfica se sugiere Cristina SEgura GraíNo, "Situación jurídica y realidad social de casadas y viudas en el medioevo hispano (Andalucía)", en La condición de la mujer en la Edad Media, Madrid, Casa de Velazquez/Universidad Complutense, 1986; Emma Montanos Ferrin, "La criminalización de los derechos del Pater familias", en Emma Montanos Ferrin y José SÁnchez Arcilla, Estudios de historia del derecho criminal, Madrid: Jacaryan, 1990; Alejandro Morín, "Matar a la adúltera: el homicidio legítimo en la legislación castellana medieval", Cahiers de linguistique hispanique médiévale, XXIV (2001).

17 1479.08.09, AGS, RGS, f. 84. 
jurados expresaron su preocupación porque en el término de un mes se avían robado más de dies casas, e que ninguna persona no se fallava quien lo fasya ${ }^{18}$. Ante tal situación, se apela a la solidaridad entre los vecinos solicitando a los habitantes de Toledo a que cada uno cierre su casa de noche encomendando a sus vecinos porque sy algo syntieren se levantes e lo remedien e prendan ${ }^{19}$. El 21 de febrero de 1486 los jurados expresaron su preocupación porque se avían fecho en esta çibdad muchos urtos asy de mulos como de otras cosas ${ }^{20}$. En 1494 el jurado Alonso Gómez de Torremilano peticiona ante el juez de residencia de Córdoba porque estando él solo en su casa fue asaltado a media noche ${ }^{21}$. En algunas ocasiones, una situación de robo conduce a una de homicidio como le sucedió en 1479 al guarda de la mina de Almadén que fue asesinado violentamente durante la noche. Según la acusación presentada por el padre de la víctima, el hecho sucedió de noche, por le robar e matar. El homicida Juan de la Cueva quebrantó las puertas de la casa y con un espada le dio muchas feridas a su víctima que se levantó y emprendió la huída. El asesino fue en pos dél e lo alcanzo e lo acabó de matar e, dexandolo así muerto desnudo en carnes, tornó a la dicha casa e tomó lo que en ella tenía, que podía valer $7.000 \mathrm{mrs}^{22}$.

En ocasiones, los ladronzuelos se dedicaban al robo de bienes y mercancías de escaso valor económico. Una nota de color la ofrece el robo de frutas puesto que los litigios que se producen por este motivo son curiosamente abundantes. Según un informe de mediados del siglo XV, el señor de Villafranca del Bierzo, Pedro Álvarez de Toledo y Zuñiga, poseía cuatro esclavos turcos que de noche eran enviados a los colmenares ajenos para buscar miel y frutas ${ }^{23}$. En 1500, las ordenanzas de la villa de Pedraza dedican un capítulo especial a aquellos que furtan de noche havas.

Otrosy ay algunos pastores o labradores o otros hombres de la villa que no aviendo verguença del mal que fazen ni parando mientes en el hierro que vehen que van de noche a furtar havas a las viñas e fazen daño en ellas desaguisados, e qualquier destos tales que asy fueren de noche a las viñas por la osadía peche por cada vez doze maravedís, e demás peche lo que cojió o llevó lo que fuere apreçiado por dos hobres buenos doblado... ${ }^{24}$

En caso de que el ladrón fuera sorprendido y atrapado por el propio dueño de la viña, se debía poner al reo en poder de los alcaldes hasta que pagase la pena. Si la insolvencia económica por parte del raptor fuera un impedimento para el resarcimiento de la víctima, el acusado era colocado en prisión por quince días.

${ }^{18}$ Ricardo Izquierdo Benito, Un Espacio Desordenado: Toledo a fines de la Edad Media, Toledo, Diputación Provincial- Universidad de Castilla-La Mancha, 1996, p. 103.

${ }^{19}$ Ibídem; p. 103.

${ }^{20}$ Ibídem; p. 103.

21 1494.02.10, AGS, RGS, f. 195.

22 1489.02.07. AGS, RGS, fols. 31 y 117. El caso es analizado exhaustivamente por Juan Miguel Mendoza GarRido, op. cit; p. 196.

${ }^{23}$ Franco Silva, A, La fortuna y el poder: estudios sobre la base económica de la aristocracia castellana. S. XIV-XV, Cádiz, Universidad de Cádiz, 1996, p. 87.

${ }^{24}$ Alfonso Franco Silva, Estudios sobre ordenanzas municipales (Siglos XIV-XVI), Cádiz, Universidad de Cádiz, 1998, doc: Ordenanzas y Acuerdos del Conçejo de Pedraza, p. 161. 
En ocasiones, la literatura medieval castellana nos describe situaciones de robos nocturnos. Los Milagros de Nuestra Señora, obra capital de Gonzalo de Berceo, es una compilación de exempla que relatan veinticinco milagros de la virgen María escritos a mediados del siglo XIII. En el milagro número XXV (La Iglesia Robada) ${ }^{25}$, el autor nos relata una situación de robo que tiene como testigo la oscuridad de la noche. La crítica acuerda en que el milagro es de asunto español pero los debates giran en torno a la fuente de inspiración puesto que Berceo tanto pudo recogerlo de la tradición oral, ya que narraba una leyenda relativamente reciente, como también pudo hallarlo en algún manuscrito dado que el propio Berceo nos declara que "en libro lo echaron". La acción transcurre durante el reinado de Fernando III el Santo cuando unos ladrones, uno ignorante y el otro un obispo, fueron guiados por el diablo a Castilla. Antes de llegar a la ciudad vieron una iglesia cercana a la casa de una monja e inmediatamente resolvieron saquear la casa y la iglesia.

\section{Barrutaron la cosa estos ambos ladrones, \\ Movieronse de noche, con sennos açadones, \\ Desquizaron las puertas, buscaron los rencones, \\ Buien entendien que era la ciella sin varones}

Cuando los ladrones se estaban por retirar, se dieron cuenta que la corona de la Virgen era valiosa. El clérigo fue a tomarla pero cuando intentó hacerlo se le quedó pegada a la mano y María les hizo perder la cabeza, para que no pudiesen y no encontraran la salida. La monja avisó a la gente, que acudió a socorrerla y encontró a los dos ladrones en la iglesia. Los ladrones recibieron azotes y el clérigo fue derivado a la justicia eclesiástica para que se decidiese su castigo. Este tipo de obras literarias que integran el género denominado "Mester de Clerecía" y que encuentran a Berceo como uno de sus principales promotores, se creaban para entrentener (delectare), enseñar (docere) e impulsar (movere) a la gente hacia estilos de vida virtuosos. El didactismo contenido en esta literatura informa a quien la lea o escuche (no hay que perder de vista la importancia de la oralidad durante el período medieval) que la noche es el terreno más propicio para cometer actos delictivos. No obstante, la solidaridad intervecinal a la cual apeló la religiosa y por supuesto la intervención mariana determinaron un feliz desenlace. Por último, no es casual que este robo nocturno esté guiado por una figura íntimamente ligada al mundo de la nocturnidad: el diablo ${ }^{26}$.

\subsection{EL TIEMPO DE TIMAR}

Los fraudes y abusos eran un tipo de delito de menor gravedad en comparación al homicidio y al robo pero no por ello menos importante. Un contexto en el que se

${ }^{25}$ El milagro XXV que nos ocupa fue añadido por el propio Berceo después de cerrada la colección de veinticuatro milagros. Con el milagro XXIV acababa uno de los códices de San Millán. Véase el estudio prologal realizado por Antonio Solalinde en Gonzalo de Berceo, Milagros de Nuestra Señora, ed. y notas de Antonio Solalinde Madrid, 1994, pp. 7-32.

26 ...Guiólos el diablo que es un mal guión. Gonzalo DE BERCEO, op. cit; p. 193. Guión es utilizado en el sentido de "guía". 
producían muchos fraudes era el comercio. Bajo el amparo de la noche, se introducían todo tipo de mercancías de manera ilegal para evitar, entre otras cosas, el pago de un arancel. Por ejemplo, en 1346 el concejo de Pedraza prohíbe el ingreso de vino foráneo en la villa durante las horas nocturnas.

...e porque esta tierra se pueble mejor ordenamos e ponemos que ningunos non sean osados de meter vino de fuera a Pedraza ni a su término...e porque en esto se fazen encubiertas e engaños que los que meten el vino de fuera traenlo de noche $e$ metenlo en sus casas encubiertamente ${ }^{27}$.

Las Ordenanzas del Concejo de Córdoba de 1435 hacen referencia a la venta de ganado robado a las carnicerías de la ciudad en las horas nocturnas.

Otrosy, por quanto acaece algunas vezes que los que furtan bueyes e vacas e las venden a los carniceros, e por que las traen de noche a las carnecerias, los señores dellas no las pueden cobrar, por ende ordenamos e mandamos que los carniceros traygan los dichos ganados de día a las carnecerias, e non de noche; e sy de noche las troxeren e fuere fallado que eran de furto, que se pare a la pena de furto // el dicho carnicero, e pague por cada vez cien mrs. para la labor de la puente e doze mrs. al mayordomo, e por que esto sea mejor guardado, mandamos que los carniceros sean obligados de fazer saber a los nuestros fieles o a qualquier dellos el ganado que compran e de quién lo compran e avn dé señales, e que los fieles lo escriuan en sus libros $^{28}$.

La reconstrucción imaginada hecha por María del Carmen Carlé de la vida en una ciudad amurallada en la meseta castellana a fines del siglo XV contempla la presencia de estos timadores. En esa ciudad ideada por Carlé que podría ser una más entre todas "dos individuos vuelven a sus casas contando dinero: han aprovechado las horas de la noche para introducir, con el mayor sigilo posible, algunas vacas robadas, que han vendido al carnicero" 29 .

Las ordenanzas del Concejo de Cuenca de 1466 regulan, entre otras cosas, distintos aspectos del mercado semanal. Al respecto, determinan que todas e cualesquier cosas e mercancias que se vynieren a vender al dicho mercado, las puedan vender e vendan dende el jueves en amanecido fasta una hora de la noche ${ }^{30}$.

Todavía en el siglo XVII, la introducción de mercancías durante la noche continúa siendo un inconveniente que preocupa a las autoridades y el Ayuntamiento de Murcia dispone que ninguna persona puede meter en esta Ciudad vino en cantidad alguna, si no fuere despues de salido el sol y antes de ponerse. Todo aquel que incumpliese la normativa debía entregar el vino a las autoridades y pagar seiscientos maravedies

${ }^{27}$ Véase Alfonso Franco Silva, Estudios sobre ordenanzas municipales...op. cit., p. 164.

28 Manuel GonzÁlez Jiménez, "Ordenanzas del Concejo de Córdoba (1435)", HID, 2 (1975), p. 271.

${ }^{29}$ María del Carmen CARLÉ, "Veinticuatro horas en la vida de una ciudad en tiempos de Isabel la Católica", en Julio Valdeón Baruque, (ed.), Sociedad y economía en tiempos de Isabel la Católica, Valladolid, 2002, p. 312.

${ }^{30}$ Citado por María Dolores CABAÑAS GonZÁLeZ, "Ciudad, mercado y municipio en Cuenca durante la Edad Media (Siglo XV), En la España Medieval, 7 (1985) p. 1723. 
de pena ${ }^{31}$. Al inicio del reinado de Felipe IV, se registra un pleito litigado por el fiscal del rey Diego de Riaño Gamboa y María Hernández, viuda y madre de los hijos menores de Gregorio Fernández de Ávila- contra Francisco de Villapando puesto que éste había matado a cuchilladas al mencionado Gregorio Fernández por haberle acusado éste por meter gran cantidad de aceite de noche, ocultamente, sin registrar y sin pagar la sisa ${ }^{32}$.

\subsection{EL TIEMPO DE ATACAR}

En último lugar, merecen ser mencionadas aquellas situaciones de agresión que no iban acompañadas de la muerte. A nuestro parecer, este tipo de delito reviste dos características importantes. La primera es que al sobrevivir la víctima siempre se conoce la identidad del agresor a través del testimonio de la parte afectada. En segundo lugar, la supervivencia de la víctima intima a los tribunales, por un lado, a expedir una sentencia y, por otro lado, a su observancia. En 1487, la jabonera Inés García pide que se cumpla una sentencia de muerte contra Juan Benito el Viejo y su hijo Martín quienes allende de otras Ynjurias que le avyan fecho et feridas que le avyan dado, una noche estando ella dormyendo la tomaron en su camara desnuda et por fuerça et contra su Voluntad la llevaron e la sacaron della e le cortaron las narices ${ }^{33}$. En 1497, se pide que se cumpla la sentencia de cortar la mano derecha a Antón Sepúlveda y a Juan de Sepúlveda, vecinos de San Martín de Valdeiglesias, por haber herido de noche a Juan Velázquez de Ibáñez Domingo, vecino de la misma vecindad puesto que los jueces Antón de Leva y Alonso Mexía así lo habían dispuesto en su fallo ${ }^{34}$. María Asenjo González ha realizado la transcripción de un documento de la ciudad de Úbeda fechado el 22 de octubre de 1509 que da cuenta de los delitos y escándalos que tuvieron lugar en dicha ciudad en el contexto de los enfrentamientos entre linajes por lo que se solicita la intervención de un pesquisidor ${ }^{35}$. El documento revela que las agresiones ocupaban parte importante del espacio nocturno. A modo de ejemplo citamos los casos de los vecinos Rodrigo Ventor y Antón Palomino. El primero de los vecinos recibió durante la noche la visita de los hijos de Alonso de Fonseca quienes le tomaron por fuerza su muger e le dieron una asaeteada en los pechos ${ }^{36}$. En el caso del segundo vecino, el documento manifiesta que siete y ocho hombres armados entraron una noche en casa de Antón Palomino y le dieron muchos golpes y

31 Ordenanzas del campo y la Huerta de Murcia aprobadas por Carlos II. Reproducción en offset de la edición de Murcia, 1695, Academia Alfonso X el Sabio, Murcia, 1981. Citado por María Trinidad LóPEz GARCíA, "La gestión del abastecimiento del vino en el Ayuntamiento de Murcia a finales del siglo XVII", Revista Murciana de Antropología, 12 (2005), p. 279.

${ }^{32}$ 1622.02, Archivo de la Real Chancillería de Valladolid, Registro de Ejecutorias, 2329, f. 27. (En adelante, ARChVa, Reg. de Ejecutorias)

33 1487.03.27, AGS, RGS, f. 94.

${ }^{34}$ 1497.05.27, AGS, RGS, f. 130.

${ }^{35}$ Véase María Asenjo GonzÁlez, "Las ciudades", en José Manuel Nieto Soria (dir.) Orígenes de la Monarquía Hispánica. Propaganda y legitimación, ca. 1400-1520, Madrid, Dykinson, 1999, Apéndice documental, doc 53, pp. 480-482.

${ }^{36}$ Ibídem; p. 480. 
espaldarazos y le cataron la casa ${ }^{37}$. Aunque la agresión sin muerte nos pueda parecer un delito menor, estas situaciones de violencia condicionaban negativamente la vida de las víctimas, especialmente cuando iban seguidas de amenazas. Este es el caso del clérigo Diego Montero que acusó a Sebastián Zorrila de injuriarle y amenazarle de muerte además de acecharle en su casa por la noche con arcabuces y espadas para intentar matarlo ${ }^{38}$. En 1593, Tomás Vélez Concha, vecino de Burgos, acusa a un vecino de la misma ciudad de nombre Diego de Salcedo de agredirle una noche despues de tenerle amenazado, dándole varias cuchilladas y cortarle el dedo pulgar de la mano derech $a^{39}$.

El conjunto de irregularidades señaladas durante la noche llevó a las autoridades a tomar cartas en el asunto. A continuación analizaremos los intentos de control de la nocturnidad que llevaron a cabo los municipios en Castilla a fines de la Edad Media.

\section{LAS LEYES DE LA NOCHE: INTENTOS DE DOMESTICACIÓN DE LA NOCTURNIDAD EN CASTILLA}

\subsection{LOS MUNICIPIOS Y SU POTESTAD NORMATIVA PARALAREGULACIÓN DE LA VIDA NOCTURNA CITADINA}

El control de la noche en las ciudades castellanas se ejerce limitando al máximo la sociabilidad. Al caer la tarde, las murallas cierran sus puertas, las rondas inician sus patrullas y los habitantes de la ciudad deben permanecer en sus casas puesto que la circulación nocturna por las calles se prohíbe salvo circunstancias excepcionales. Todo aquel que se mueve por la noche después del toque de queda debe hacerlo desprovisto de armas y portando luz para hacer menos dificultosa la identificación del individuo. Los marginales y los forasteros serán los grupos sospechosos por excelencia si son sorprendidos merodeando las calles en las horas nocturnas.

Es importante recordar que los concejos tenían potestad normativa, es decir, la organización interna de las poblaciones estaba regulada por las normas que dictaba el municipio. El mantenimiento de la paz y el orden social era una de las preocupaciones primarias que se detecta con reiteración a lo largo de fueros y ordenanzas. A su vez, eran competencias del municipio la administración de justicia, la organización del sistema de policía y cuestiones relativas al abastecimiento, limpieza de calles, beneficencia y el control de las actividades nocturnas, entre otras. La multiplicación de ordenanzas en los siglos XV y XVI es un aspecto que merece ser señalado. Según Corral, las ordenanzas municipales desarrollan el fuero, el cual había caído en un proceso de degradación normativa ${ }^{40}$. Creemos que también se puede pensar que la multiplicación de ordenanzas a fines de la Edad Media responde a necesidades más puntuales de la comunidad en un contexto específico, no previstas en el fuero como

\footnotetext{
${ }^{37}$ Ibídem; p. 481.

38 1598.06.03, ARChVa, Reg. de Ejecutorias 1740, f. 10.

39 1593.02.25, ARChVa, Reg. de Ejecutorias, 1733, f. 16.

40 Esteban Corral García, Ordenanzas de los concejos castellanos. Formación, contenido y manifestaciones (Siglos XIII-XVIII), Burgos, 1988, p. 28.
} 
norma local, ni tampoco en ordenamientos más amplios ${ }^{41}$. Las ordenanzas expresan el deseo por parte del municipio o villa de dotarse de una reglamentación completa de todas sus actividades (administrativas, judiciales, preservación del término y los recursos, etc) $)^{42}$.

Es significativo destacar la potestad normativa de los municipios puesto que los textos legislativos que ellos producen son una fuente de primera mano para el estudio de las actividades nocturnas en el contexto urbano. En Castilla, los diferentes municipios implementaron diferentes tipos de estrategias con el fin de "domesticar" la nocturnidad, es decir, buscar un control de aquel momento del día colmado de peligros mundanos tan reales como peligrosos según hemos visto en nuestras fuentes. A esta documentación elaborada por los municipios, debemos yuxtaponer fuentes regias, nobiliarias, eclesiásticas y literarias para poder hacernos una idea más o menos completa sobre las preocupaciones que invadían a las autoridades medievales desveladas en su búsqueda por encontrar diferentes estrategias que les permitiesen tener un control de la nocturnidad.

En el siguiente apartado, nos abocaremos al estudio de las distintas estrategias y/o herramientas preventivas que se implementaron en Castilla con la intención de "domar" la nocturnidad.

\subsection{LOS LÍMITES A LA CIRCULACIÓN NOCTURNA, EL TOQUE DE QUEDA Y LA PORTACIÓN DE LUMBRE ENCENDIDA}

En todas las ciudades castellanas, el toque de la campana que seguía a la puesta del sol marcaba la finalización del régimen diurno y el comienzo del régimen nocturno. Una vez iniciado el toque de queda, los habitantes tenían prohibido circular libremente por las calles salvo circunstancias excepcionales. En caso de ser sorprendidos durante la noche deambulando por las calles debían hacerlo sin armas y portando una luz encendida a fin de minimizar el anonimato y facilitar el reconocimiento de los mismos a la distancia ${ }^{43}$.

Izquierdo Benito recoge varias disposiciones aprobadas por el Ayuntamiento de Toledo a fines del siglo XIV que fueron integradas en sus ordenanzas. En dicha documentación se establece que algunas personas andaban de noche, en tiempos desordenados, con armas vedadas, feriendo e matando e robando los omes en las calles, e furtando en sus casas. Las autoridades toledanas mandaron que esto no se volviese a hacer y que nadie, en adelante, anduviese de noche con armas devedadas, syn traer consygo lumbre açendida por que se pueda conoçer quien son. El infractor

${ }^{41}$ Véase Esteban de Vega y Antonio Morales Moya, Castilla en España. Historia y representaciones, Salamanca, Universidad de Salamanca, 2009, p. 47.

42 Véase Miguel Ángel Ladero Quesada, "Las ordenanzas locales. Siglos XIII-XVIII", En la España Medieval, 21 (1998); Pedro Antonio Porras Arboledas, "Las Ordenanzas municipales. Algunas propuestas para su estudio y un ejemplo", Espacio, Tiempo y Forma, Serie III, Historia Medieval, t. 7 (1994).

${ }_{43}$ Es posible realizar un paralelismo con el caso francés puesto que el conjunto de medidas sancionadas en dicho territorio son asimilables a las que encontramos en Castilla. "It was recommended not to go out at night, that is, after curfew, without a valid reason. Those who had to risk venturing out of doors were asked to carry torches and candles" Jean VerDON, op. cit; p. 79. 
de la norma que fuese sorprendido después de la campana del Ave María tannida en la iglesia mayor de Santa María sufriría un encarcelamiento de 30 días y se le retirarían las armas. En caso de que el agresor se resistiese a la autoridad, la justicia podía ejecutarlo ${ }^{44}$. En julio de 1475, se pregonó que ninguna persona sea osado de andar de noche despues de tanida la canpana a pie salvo trayendo lenterna o candela ${ }^{45}$. En 1478 se volvió a pregonar que ningunas personas non sean osados de andar a pie despues de tannida la canpana del Ave María de la Yglesia Mayor e sy anduviere que trayan candela ençendida so pena que queal quiera que fallare que no lleva candela ençendida que le llevaran preso a la cárçel ${ }^{46}$. En el caso toledano, la restricción de la circulación nocturna es una constante que se registra en una cantidad importante de pregones y ordenanzas.

Pero esta situación que venimos analizando no es exclusiva de la "ciudad imperial" pues encontramos una normativa similar en numerosas ciudades del Reino de Castilla. En las ordenanzas de Riaza de 1457 se prohíbe andar de noche y portar armas desde una ora después que sea anocheçido fasta dos horas después de media noche. Los infractores de la norma tenían que pagar una multa de $500 \mathrm{mrs}$; la mitad para el concejo y la otra mitad para la justicia, además de permanecer diez días en la cadena ${ }^{47}$. El análisis de la fuente legislativa pone de manifiesto que la mayor preocupación de las autoridades de Riaza reside en limitar las destrucciones, hechos de violencia, alborotos y otros actos destructivos que pueden perjudicar a individuos particulares o al colectivo social. La importancia de restringir la circulación nocturna es justificada por las autoridades de la siguiente manera:

Las gentes andan de noche por esta villa faziendo algunas cosas desaguisadas, ansi trastornando carretas e chorros e desfaziendo otros edificios, e cosas de ynormedades e muy feas, e mudando sus fablas e vozes, e traen armas e andan ascondidamente, mudando los traies e visaies ${ }^{48}$.

En las ordenanzas de Ávila se destaca que algunos non fuesen osados de andar por la dicha villa de noche desque fuer tañida la canpana de la iglesia, o bien, después de dadas las nueve oras de la noche ${ }^{49}$. En Carmona, el incumplimiento del toque de queda sin ninguna justificación llevaba aparejado el encarcelamiento inmediato del transgresor de la norma hasta la mañana siguiente y el cobro de una multa de $4 \mathrm{mrs}$. de carcelaje ${ }^{50}$.

En las villas de Tolox y Monda, dominios del Marqués de Villena, sus ordenanzas de 1552 contemplan el encarcelamiento y la pena pecuniaria $(200 \mathrm{mrs})$ como castigo

${ }^{44}$ Ricardo Izquierdo Benito, op. cit; p. 120.

${ }^{45}$ Ibídem; p. 266, apéndice documental, doc. 79.

${ }^{46}$ Ibídem; p. 229, apéndice documental, doc. 82.

47 Antonio Ubieto Arteta, Colección diplomática de Riaza (1258-1457), Diputación Provincial, 1959, pp. 185-186.

${ }^{48}$ Idídem; p. 185.

49 José María Monsalvo AnTón, Ordenanzas Medievales de Ávila y su tierra, Diputación Provincial, 1990, pp. 188 y 193.

${ }^{50}$ Manuel GonzÁlez Jiménez, Ordenanzas del concejo de Carmona, Sevilla, Diputación Provincial, 1977, p. 25. 
para cualquiera persona que anduviere vna hora después de anocheçido sin portar candela o hachón de madera. La única justificación válida que exonera al acusado de la pena es demostrar que se encontraba acompañando a una mujer porque en tal caso se presume yr seguro ${ }^{51}$.

Las ordenanzas de Baeza expresan una preocupación de índole moral puesto que de noche van a la fuente principal de esta çibdad muchas personas neçesitadas, mugeres, e mugeres casadas, e biudas, e moças e muchos moços e otras personas con poco temor van a la dicha fuente e hazen muchas descortesías ${ }^{52}$.

\subsection{EL CONTROL DEL USO DE LAS ARMAS}

La instauración del toque de queda, la restricción de la circulación nocturna y la obligatoriedad de llevar lumbre encendida se presentaban como medidas preventivas insuficientes para un poder político que buscaba asegurarse un dominio más o menos integral de la nocturnidad. Las autoridades apostaron por una nueva medida: el control del uso de las armas en horas nocturnas. Antes de avanzar sobre este punto, es importante señalar que durante el día también se limitaba el uso de armas ya que estaban prohibidas aquellas consideradas ofensivas permitiendose únicamente el uso de armas defensivas (espada y puñal).

Los muy honorables sennores corregidor e Toledo hordenan e mandan que desde oy en adelante ninguna ni algunas personas de ningund estado o condiciçion que sean no sean osados de traer ni trayan ningunas armas ofensyvas ni defensyvas de noche ni de dya ellos ni sus omes e criados despuelas ni anden de noche despues de dada la canpana ${ }^{53}$.

La documentación pone de manifiesto que a la puesta del sol, la legislación en relación al uso de armas se vuelve más severa y represiva. La nocturnidad actúa como circunstancia agravante. Las ordenanzas municipales antiguas de 1400 de la ciudad de Toledo ilustran lo antes dicho en su capítulo LXV (Que fabla del ordenamiento fecho que non anden de noche con armas devedadas por la çibdat)

Manda Toledo e tiene por bien, que por quanto les fue dicho e denungiado que algunas personas, non temiendo a Dios nin a la justicia de nuestro señor el rey e con gran osadía e atrevimiento e otrosi en gran menospregio de la justigia, que andan de noche, en tiempos desordenados, con armas vedadas, firiendo e matando e robando los omes en las calles e furtando en sus casas, e faziendo otros malefigios, que estos omes tales que ansi andan faziendo estos tales malefigios e otros semejantes dellos. Que de aqui adelante se castiguen e corrigan, e non sean osados nin se atrevan de lo así fazer.

E otrosi, (CXXXIIIIv) que asi ellos como otros qualesquier, personas de qualquier

${ }^{51}$ Alfonso Franco Silva, Estudios sobre ordenanzas municipales...op. cit., p. 32.

${ }^{52}$ Carmen Argente del Castillo Ocaña, "Reglamentación de la vida de una ciudad en la Edad Media. Las Ordenanzas de Baeza", Cuadernos de Estudios Medievales, VIII-IX (1980-1981), Granada, 1983, p. 73.

${ }_{53}$ Ricardo Izquierdo Benito, op. cit; apéndice documental: pregón difundido por Toledo s/f, p. 244. 
ley o estado o condigión que sean, non anden de noche de aquí adelante con armas devedadas sin traer consigo lumbre engendida, por que se puedan conoger quién son.

En otra manera, si lo así non fiziere o cumpliere e fueren tomados después de la campana del Ave María tañida de la iglesia mayor de Santa María, que pierdan las armas que troxieren e sean puestos en la prisión del rey que es en esta gibdat, e que estén y presos treinta días. E si se quisieren defender de la justigia del rey, non queriendo darse a prisión, que los pueda matar la justigia e los que con ellos fueren sin pena alguna. E si para complir esto que dicho es, la justigia oviere menester ayuda, asi de noche como de día, manda a los vezinos e moradores en la collagión e barrio o calle do esto acaesgiere que, a la boz e clamor de la justigia, salgan todos con sus armas a la ayudar e esforgar, en tal manera que se cumpla enteramente la justigia del rey, e los dichos malfechores sean castigados por justigia. En otra manera, si por culpa e negligengia de los tales vezinos e moradores de Toledo que esto sopieren e (CXXXVr) oyeren, e lo así non quisieren fazer e complir, e algún peligro viniere a la justigia o deservigio al rey o a Toledo e daño a los vezinos e moradores de Toledo, quel rey e Toledo se torne por ello a ellos e a sus bienes e cabegas ${ }^{54}$.

El uso de armas vedadas durante la noche se entiende como un desafío directo a la autoridad real; en consecuencia debe ser castigado con severidad. En términos cronológicos, esta legislación toledana coincide con un contexto de inestabilidad política interna que afectó a los gobiernos de los últimos reyes Trastámara. En Toledo durante el siglo XV, se vivieron algunas situaciones de sublevación que es importante tener en consideración al momento de analizar la documentación existente ${ }^{55}$. Pero la circulación nocturna agravada por la portación de armas es también un desafío a la divinidad. La iglesia abonaba la idea de que el tiempo era sagrado y de propiedad divina; según esta concepción espiritual la noche era el espacio de la oración y el descanso. Cualquier perturbación que afectara este esquema ideado por la Iglesia se entendía como un ataque a la institución misma. En relación a los sujetos sobre los cuales la legislación era aplicable, el texto no deja margen a ningún tipo de dudas puesto que habla de personas de qualquier ley o estado o condiçión que sean. El caso murciano reviste una particularidad que no podemos dejar de mencionar puesto que a finales del siglo XIV la prohibición de portar armas durante la noche está especialmente dirigida hacia los clérigos que fazen algunos malefiçios. Un castigo especialmente severo se aplica a los clérigos de corona, es decir, aquéllos que sólo tenían la primera tonsura.

E otrosi ordenaron e mandaron los dichos omes buenos e ofiçiales que si el alguaçil fallara andando de noche por la çibdat después de la canpana del aguazil tañida algunos clérigos asi de ordenes sacras o beneficados como de coronas andando desordenadamente con armas, quel alguaçil que les tome las armas y las quiebre e cuelge la metad dellas a la puerta de Santa María desta dicha çibdat y la otra meatad

${ }^{54}$ Citado por Pilar Morollón Hernández, "Las ordenanzas municipales antiguas de 1400 de la ciudad de Toledo", Espacio, Tiempo y Forma, Serie III, H. Medieval, t. 18 (2005), p. 396.

${ }_{55}$ Para un detallado análisis de los enfrentamientos que tuvieron lugar en Toledo durante esta centuria véase Eloy Benito Ruano, Toledo en el Siglo XV: vida política, Madrid, CSIC, 1961. 
en la corte, e los clérigos de orden sacra que las llieue a poder ofiçial de la eglesia e los clérigos de corona que los echen en la presion de la corte ${ }^{56}$.

Incluso después del Concilio de Trento, el sínodo murciano celebrado por Don Jerónimo Manrique de Lara en 1583 manda, entre otras cosas, que los clérigos no porten armas durante la noche. Si fueran sorprendidos con las dichas armas, con hábitos deshonestos o con instrumentos musicales luego del toque de queda serían apresados por los alguaciles a la vez que se les aplicaría una pena de $600 \mathrm{mrs}$. acompañada de la incautación de las armas y/o instrumentos musicales ${ }^{57}$.

Volviendo al caso toledano, en sus ordenanzas encontramos referencias al tipo de armas vedadas. En forma explícita se prohíbe que cualquier hombre llevase cotas nin baginetes ni caxquetes nin fojas ni broqueles nin escudos ni adaragas, nin langas nin dardos nin porqueras nin fachas ${ }^{58}$. Sólo los oficiales de justicia podían portar armas y cualquiera que incumpliese esta disposición, por primera vez le confiscarían las armas, la segunda vez estaría 30 días en la cárcel y la tercera vez le darían 50 azotes públicamente por la ciudad. El 24 de enero de 1474 se pregonó en la ciudad de Toledo que ninguno podía llevar armas ofensivas ni defensivas después de tannida la campana del Ave María de la santa yglesia desta dicha çibdad. El castigo consistía en la confiscación de las armas por y para los alguaciles que luego llevarían al sujeto en cuestión a la cárcel, donde sería castigado ${ }^{59}$.

El análisis de la documentación municipal de Chinchilla pone de manifiesto la preocupación de las autoridades para evitar enconamientos e roydos. A tal efecto, se resuelve limitar la circulación nocturna con armas. El 21 de febrero de 1461 en la ciudad de Chinchilla reunidos el corregidor, los regidores, los alcaldes, el alguacil, un jurado y algunos testigos ante el escribano y notario público de la dicha ciudad se determinó que serían incautadas las armas a todos aquellos hombres que las portaran luego de que se hubiese iniciado el toque de queda. Esta medida venía a cubrir un bache legal puesto que las ordenanzas de Chinchilla no hacían referencia a cómo se debía actuar en este tipo de situaciones; por otra parte, el documento expresa que la esencia de la medida es preventiva puesto que incautando las armas se buscaba evitar los enconamientos e roydos ${ }^{60}$. El estudio realizado por González Jiménez de las ordenanzas del Concejo de Córdoba en 1435 pone de manifiesto que con el objeto de asegurar el bien público, las ordenanzas autorizan el encarcelamiento de todo aquel que llevase armas de noche ${ }^{61}$. Asimismo, las ordenanzas de La Alberca y sus términos

${ }^{56}$ Citado por José Bernal Peña, "Golfines y asesinos. Marco legal del delito durante la Edad Media. Detalles de Murcia durante el siglo XIV”, Miscelánea Medieval Murciana, 35 (2011), apéndice doc n 1, p. 46.

57 Lope Pascual Martínez, "En torno al Sínodo Murciano de Don Jerónimo Manrique de Lara (1583)", Estudios Románicos, vol. 6, (Homenaje al Prof. Luis Rubio, t. 3) Murcia, 1990, p. 1741.

58 Pilar Morollón Hernández, op. cit; p. 397.

${ }^{59}$ Ricardo IzQuierdo Benito, op. cit; apéndice documental: pregón difundido por Toledo el 14 de agosto de 1473, p. 221.

${ }^{60}$ Amparo Bejarano Rubio y Ángel Luis Molina Molina, Las ordenanzas municipales de Chinchilla en el siglo XV, Murcia, Academia Alfonso X El Sabio y Universidad de Murcia, 1989, pp. 189-190.

${ }^{61}$ Véase Manuel GonZÁLEZ JiMÉnEZ, op. cit; pp. 201-202. 
Las Hurdes y Las Batuelas dedican una sesión específica a este asunto intitulada Ordenanza de las Armas en donde se dispone que no sea ninguno osado vecinos desde dicho lugar, ni de su pertenençia ni de fuera parte, de traer armas de noche ni de dia por el dicho lugar. Si algún hombre fuera sorprendido portando armas de día debería pagar una pena de $100 \mathrm{mrs}$. para la cámara del duque y asimismo perdería las armas que pasarían a propiedad de la justicia. Si el delito es cometido de noche, sea la pena doblada, e mas que esté [quien quebrante la ley] tres dias en la cadena ${ }^{62}$. Cuando un delito tiene lugar en el espacio de la nocturnidad, el castigo es siempre más severo. Esto último se aplica en un sentido amplio a diferentes tipos y niveles de delincuencia dado que la noche es uno de los grandes agravantes de la justicia medieval ${ }^{63}$.

\subsection{EL PODER DE LOS ALGUACILES}

Los peligros mundanos asociados a la noche medieval eran tan reales como el interés de las autoridades por controlarlos. A fines de la Edad media, el poder de los alguaciles mayores se fortalece adquiriendo "una capacidad coactiva y exactiva que deja un amplio margen de actuación y que se presta, como se ve reflejado en bastantes quejas, a la prevaricación, al chantaje y a la corrupción" ${ }^{4}$. La documentación nos presenta a los alguaciles como los responsables del mantenimiento del orden y de la persecución del crimen en el mundo urbano castellano. A los alguaciles del concejo se les sumaban los alguaciles de corte que estaban encargados de aquellos casos que excedían la jurisdicción de un determinado concejo. A este cuerpo judicial lo completaban los cuadrilleros y hombre de armas de la Hermandad que actuaban en el ámbito rural. El alguacilazgo municipal estaba regenteado por el llamado Alguacil Mayor, un cargo de enorme importancia. M. A Ladero Quesada ${ }^{65}$ sostiene que el alguacil mayor de Sevilla era un cargo que aparece desde la conquista y además revestía carácter vitalicio. El rey era quien nombraba en su cargo al alguacil mayor y por lo tanto el puesto solía beneficiar a miembros de la nobleza o de la oligarquía urbana. En Sevilla, el cargo estuvo vinculado durante todo el siglo XV a los Guzmán y en Jaén fue el propio Miguel Lucas de Iranzo el titular de este oficio durante mucho tiempo. Subordinados al alguacil mayor, encontramos a los lugartenientes del alguacil o alguaciles menores que en el caso cordobés eran denominados "alguaciles de espada" $"$.

A continuación nos ocuparemos brevemente del estudio del alguacilazgo en Córdoba a fin de profundizar nuestros conocimientos en relación a esta figura de

${ }^{62}$ Gabrielle Berrogain, "Ordenanzas de La Alberca y sus términos Las Hurdes y Las Batuelas”, AHDE, 7 (1930), p. 399.

${ }^{63}$ Partida VII, título XXXI, ley VIII.

${ }^{64}$ Juan Miguel Mendoza Garrido, op. cit; p. 444.

${ }^{65}$ Miguel Ángel Ladero Quesada, Andalucia en el siglo XV. Estudios de historia política, Madrid, CSIC, 1973, pp. 79-80.

${ }^{66}$ En tiempos de los Reyes Católicos el número fijado de alguaciles de espada era quince, es decir, uno por parroquia o collación donde, además, tenían la obligación de residir. Véase José Luis del PINO GARCIA, "El Concejo de Córdoba a fines de la Edad Media: estructura interna y política municipal", HID, 20 (1993), p. 363. 
vital importancia en las ciudades castellanas durante las horas nocturnas. El cargo de Alguacil Mayor de la ciudad de Córdoba estuvo en manos de los Fernández de Córdoba desde finales del siglo XIII, cuando el titular era Alfonso Fernández de Córdoba, quien, a su vez, había sucedido a su padre en el ejercicio del cargo ${ }^{67}$. En un trabajo de Cabrera Sánchez ${ }^{68}$, la autora postula que el caso cordobés pone de manifiesto un proceso de patrimonialización no consolidado del todo puesto que el mismo cargo de alguacil mayor fue ejercido también por Pay Arias de Castro en 1301 y 1305. De todos modos, pese a los avatares sufridos en este proceso de patrimonialización del cargo, el mismo estuvo siempre ligado a los miembros de la familia Fernández de Córdoba ${ }^{69}$. A mediados del siglo XIV el cargo derivó hacia una de las ramas de dicha familia, la de los señores de Baena. El primer señor de Baena, Diego Fernández de Córdoba, comenzó a ostentar el cargo en 1386 y lo transmitió sin interrupción a sus sucesores hasta el siglo XVI. En 1435 por concesión de Juan II el primer Conde de Cabra, nieto de Diego Fernández de Córdoba, se transforma en alférez mayor de Córdoba. La continuidad de la familia señorial de Baena y Cabra en el disfrute del cargo de alguacil mayor se explica a partir de que "los miembros de esa casa tuvieron una relación muy estrecha con la realeza"70.

En general, siempre son las cabezas de linaje quienes ostentan el alguacilazgo y lo combinan con el de mariscal de Castilla y señor de Baena, y luego, de Cabra. ¿Cuáles eran las funciones atribuidas al alguacil mayor? ¿Cómo se vinculan con la seguridad ciudadana y en particular con los peligros derivados de la nocturnidad? Según las ordenanzas del Concejo de Córdoba el alguacil mayor tenía dos obligaciones básicas. En primer lugar debía ejecutar los mandamientos judiciales (sólo podían prender y encarcelar con mandamiento de los alcaldes mayores). Por otra parte, eran los responsables de mantener el orden público. A fin de poder garantizar esto último, el alguacil mayor estaba autorizado a encarcelar a los que llevasen armas de noche o deambulasen, también de noche, por las calles sin llevar velas o candelas encendidas puesto que de esta forma se prevenían alborotos y riñas. Durante la noche, el alguacil tenía una capacidad de actuación mayor puesto que la limitación de no poder apresar a ninguna persona sin autorización de los alcaldes, perdía vigencia al iniciarse el toque de queda dotando al cargo de atribuciones extraordinarias ${ }^{71}$. Esta situación no es privativa del concejo de Córdoba. En 1484, el Marqués de Cádiz D. Rodrigo Ponce de León otorga a su lugar de Chipiona una ordenanza sobre el alguacilazgo en donde determina que qualquier onbre que fuere tomado por el Alguasil de noche despues de la campana tañida andando por el lugar con armas sin cabsa debe ser llevado a la

${ }^{67}$ María Concepción Quintanilla Raso, "Nobleza y señoríos en Castilla durante la Baja Edad Media", Anuario de Estudios Medievales, 14 (1984), p. 31.

${ }^{68}$ Margarita CABrera SÁnChez, Nobleza, oligarquía y poder en Córdoba al final de la Edad Media, Córdoba, Universidad de Córdoba-Obra Social y Cultural de Cajasur, 1998, p. 96.

${ }^{69}$ No hay que perder de vista que este proceso tiene lugar durante el agitado reinado de Fernando IV que provocó una división política en la ciudad. Es lícito asimismo pensar que puede haber existido una simultaneidad en el ejercicio o en la reivindicación del cargo. Véase Emilio CABRERA MuÑoz, "Orígenes de señorío de Espejo y formación de su patrimonio territorial (1297-1319)", En la España Medieval, Homenaje al Prof. Salvador de Moxó, II, (1982), p. 215.

${ }^{70}$ Margarita CABrera SÁnchez, op. cit., p. 96.

${ }^{71}$ Manuel GonZÁlez JimÉneZ, op. cit; pp. 201-202. 
cárcel y permanecer preso tres días en cadena. En el mismo texto, se determina que las armas incautadas sean para el Alguacil ${ }^{72}$. Estos encargados de la seguridad urbana eran, asimismo, los responsables de organizar las rondas nocturnas.

\subsection{LAS RONDAS NOCTURNAS}

R. Córdoba de la Llave afirma que la noche era un escenario potencialmente propicio para la criminalidad y las conductas deshonestas; por lo tanto "todos los núcleos urbanos de cierta importancia contaron con una ronda nocturna encargada de la vigilancia de las puertas, calles y lugares públicos, y en especial de las áreas urbanas más conflictivas"73. Estos encargados de la seguridad nocturna no existieron únicamente en Castilla. En Venecia, funcionaron los llamados signori di notte que se encargaban de la vigilancia de la ciudad durante la noche. En palabras de CrouzetPavan, "la repressione della criminalità è, per i Signori di notte, la più evidente tra le funzioni ad essi attribuite" ${ }^{\prime \prime}$. En 1415 en Firenze, el servicio de vigilancia nocturna estaba dotado de seiscientos hombres que rotaban en guardias de trescientos por vuelta ${ }^{75}$. Para el caso francés, Verdon afirma que "several royal decrees show that the night guard was first a duty of the crafts, but they were assisted by a royal guard made up of mounted sergeants and armed foot soldiers" ${ }^{\text {" }}$. Es difícil cuantificar los hombres necesarios para realizar las rondas diurnas y nocturnas puesto que la cantidad de población y la situación política eran factores que contribuían en gran medida. El 12 de octubre de 1464, el duque de Bretaña organizó la guardia del castillo y la ciudad de Clisson. Dieciocho hombres estaban de guardia todas las noches: siete pertenecían a la jurisdicción de Clisson, los otros once no pertenecían, pero debido a la situación política se vieron obligados temporalmente a cumplir esa función. Verdon estima que si asumimos un período de servicio cada mes, quinientos cuarenta hombres fueron necesarios para proteger la ciudad francesa en horas nocturnas. Por lo tanto, más allá de que nos veamos imposibilitados de determinar el número de guardias nocturnos "more men were needed at night than during the day" ". En la noche francesa, existían procedimientos legales para evitar hacer la guardia nocturna. El primero era denominado "reemplazo" y consistía en encontrar a alguien capaz de realizar el servicio en el lugar del hombre ausente. Un hijo podía reemplazar al padre, un sirviente al amo. En segundo lugar, encontramos el procedimiento del "intercambio" entre personas que pertenecen a la misma jurisdicción o de jurisdicciones vecinas. Por último, existía el denominado "abono"; en tales circunstancias las autoridades

${ }^{72}$ Alfonso Franco Silva, Estudios sobre ordenanzas municipales ...op. cit., p. 277.

${ }^{73}$ Ricardo CóRdoba DE la Llave, "Marginación social y criminalización de las conductas", en Medievalismo, 13-14, (2004), p. 311.

${ }^{74}$ Elisabeth Crouzet-PAVAn, "Potere politico e spazio sociale: il controllo della notte a Venezia nei secoli XIII-XV", a cura di Mario Sbriccoli (ed.) La Notte. Ordine, sicurezza e disciplinamento in età moderna, Ponte alle Grazie, 1991, p. 50.

${ }^{75}$ Silvia MANTINI, "Notte in città, notte in campagna tra Medioevo ed Età Moderna $\square$, a cura di Mario Sbriccoli (ed.) La Notte. Ordine, sicurezza e disciplinamento in età moderna, Ponte alle Grazie, 1991, p. 31.

76 Jean VERDON, op. cit; p. 89.

${ }^{77}$ Ibídem; p. 93. 
pedían una suma de dinero en reemplazo de la guardia ${ }^{78}$. En Valencia, existía una guardia urbana encargada de la persecución de los malhechores. Dicha vigilancia estaba a cargo de un magistrado municipal denominado "el justicia" que junto a los caporales a su servicio y los vecinos de las parroquias enrolados en la ronda nocturna buscaban garantizar el orden público ${ }^{79}$.

El 27 de mayo de 1475, el Cabildo de Jurados de Toledo informa a Isabel la Católica que los vecinos y parroquianos no quieren cumplir con su obligación de rondar la ciudad. Inmediatamente, Isabel expidió una carta mandando que todos los vecinos que fuesen requeridos por los jurados para velar e rondar e guarda de la dicha çibdad cada que fuere neçesario e faser todas la otras cosas complideras al paçifico estado della, se juntasen con ellos, cada uno en su correspondiente parroquia ${ }^{80}$. En 1496, la reina católica ordena al corregidor de Guipúzcoa que se ponga de acuerdo con el Capitán Diego López de Ayala y que ambos procuren que los pueblos cercanos den las velas necesarias para la seguridad de la dicha villa ya que las ocho velas que tenían cada noche no garantizaban el orden en las calles ${ }^{81}$. En Ávila, su corregidor el licenciado Juan Pérez de la Fuente tenía entre sus obligaciones organizar las rondas para que cesen los escándalos y que se apresen a los ladrones y malhechores ${ }^{82}$. En cualquier caso, los investigadores que han estudiado el tema en los distintos reinos medievales insisten que las rondas urbanas eran cuerpos de seguridad absolutamente insuficientes para las necesidades de ciudades en constante expansión.

"Para velar por el orden se organizaban las correspondientes rondas tan pronto caía la noche, pero las más de las veces sólo eran capaces de comprobar el delito consumado" $"$.

Córdoba de La Llave también insiste en remarcar la utilidad limitada de las rondas nocturnas "que no podrían garantizar, ni por su número de efectivos, ni por la propia eficacia policial, la seguridad en los distintos barrios de cada urbe" ${ }^{84}$. De acuerdo al citado autor, el reclamo efectuado por parte de las autoridades concejiles de solidaridad vecinal con los oficiales de justicia, al momento de presentarse un conflicto, muestra la imposibilidad del poder político en Castilla para afrontar por sí mismo la prevención del crimen valiéndose de las rondas de vigilancia.

${ }^{78}$ Ibídem; pp. 93-99.

79 Rafael Narbona Vizcaíno, "La milicia ciudadana de la Valencia medieval", Clio\&Crimen, n³ (2006), pp. 305-332.

${ }^{80}$ Ricardo Izquierdo Benito, "La noche de Toledo en el siglo XV", Toletum, 30 (1994), p. 138.

${ }^{81}$ 1496.08.25, Archivo Histórico Nacional (AHN, en lo sucesivo), Sección Nobleza, Archivo de los Duques de Frías, C.18, D. 70.

${ }_{82}$ 1496.07.16, AGS, RGS, f. 73.

83 Ángel Luis Molina Molina, La vida cotidiana en la Palencia Medieval, Palencia, Diputación Provincial, 1998, p. 37.

${ }^{84}$ Ricardo CóRdoba de LA Llave, "Marginación social y criminalización...”, op. cit., p. 311. 


\subsection{LAS RESTRICCIONES AL INGRESO DE FORASTEROS}

El sistema de vigilancia nocturno estaba también enfocado hacia el control de la población marginal y de los forasteros. Los pobres, los vagabundos y las gentes sin oficio eran los principales sospechosos ante cualquier situación delictiva. En algunas ciudades castellanas, existía una "policía de pobres" aunque en general siempre eran los alguaciles quienes se encargaban de la vigilancia al interior del recinto amurallado. Por su parte, es sabido que los forasteros han sido considerados históricamente como un segmento poblacional peligroso. En Castilla, se tendió a prevenir la llegada y el establecimiento de forasteros porque se entendía que eran delincuentes en potencia que introducirían con su llegada nuevos conflictos en la vida ciudadana. En Toledo, el 24 de enero de 1474 se mandó que todos los estrangeros e personas que son venidos a esta çibdad de poco acá, e no tienen sennores ni ofiçios ni viben dellos, que de oy en segundo día, salgan desta çibdad, so pena de muerte ${ }^{85}$. Cualquier mesonero que acogiere a éstos forasteros sufriría la pérdida de sus bienes. Al año siguiente, un pregón difundido en dicha urbe otorga un plazo de tres días para que todos los proxenetas, vagabundos y gentes sin oficio abandonasen la ciudad.

Mandan los sennores Toledo que por quanto son ynformados que muchas personas ay en esta dicha çibdad de muy mal bevir revolviendo ruydos e faziendo otros grandes males e dannos lo qual era e es en grand menospreçio de Dios Nuestro Sennor e de la Justiçia del rey e reyna nuestro sennores Queriendo en ello prover mandan e defyenden que todos los rufianes que tienen mugeres e quales quier vagamundos e personas que no tienen fasyendas ni ofiçios de que biven que fasta terçero dia primero salga desta çibdad e de su jurisciçion e no entren en ella so pena que por la primera ves que lo quebrantaren le den çient açotes e por la segunda mueran por ello ${ }^{86}$.

Este tipo de disposiciones se repiten con asiduidad en diferentes ciudades castellanas. El estudio del mundo delictivo en Murcia durante el siglo XIV realizado por J. Bernal Peña evidencia que "la noche reunía tras el sutil velo de la oscuridad y la pesada capa del anonimato a todos aquellos seres que por circunstancias de la vida habían sido desplazados o intentaban huir de la convivencia diaria"87. Las ordenanzas de la ciudad de Murcia de 1536, muestran una intensa vida nocturna de personajes marginales. Las autoridades del concejo murciano introducen una serie de medidas para limitar el ingreso de forasteros y también de esclavos puesto que éstos últimos son el causante de robos y otros delitos en las horas nocturnas ${ }^{88}$. Por último, en relación a la población marginal, nos interesaría resaltar que durante las horas nocturnas se acentúan las precauciones en las prisiones para evitar la fuga de los delincuentes. No basta que el carcelero mayor cierre, por su propia mano, todas las puertas; debe recurrir a las cadenas y los cepos, que también cerrará personalmente;

85 Ricardo IzQuierdo Benito, Un Espacio Desordenado...op. cit., apéndice documental: pregón difundido por Toledo el 24 de enero de 1474, p. 222.

86 Ibidem; p. 225.

87 José Bernal Peña, op. cit., p. 40.

88 José Damian González Arce, Ordenanzas de la Ciudad de Murcia (1536), Murcia, Universidad, Servicio de Publicaciones, 2000, pp. 51-53. 
la luz encendida y el hombre de guardia tienen por función que el preso no pueda limar sus cadenas o candados durante las horas nocturnas.

$E$ de noche los deuen guardar en esta manera, echandolos en cadenas, o en cepos, e cerrando las puertas de la carcel muy bien, e el carcelero mayor deue cerrar cada noche las cadenas, e los cepos, e las puertas de la carcel con su mano mesma, e guardar muy bien las llaues, dexando omes dentro con los presos, que los velen con candela toda la noche, de manera que non puedan limar las prisiones... nin se puedan soltar..., e luego que sea de dia, e el sol salido, deuenles abrir las puertas de la carcel porque vean la lunbre- E si algunos quisiessen fabloar con ellos, deuenlos... sacat fuera vno a vno...estando delanted aquello que los han de guardar ${ }^{89}$.

Un documento de 1496 dirigido a los alcaldes de Corte y Chancillería de Ciudad Real analiza la culpabilidad que pudo tener Alonso de Quesada que era alcalde de la cárcel de la ciudad de Sevilla cuando el día de Año Nuevo se le escaparon de la cárcel, a media noche, varios presos ${ }^{90}$. A fines del siglo XVI, un vecino de Toledo de nombre Bernardino de Tobar esperaba a Diego de Luceña en el zaguán de la cárcel para quitarle las llaves de la misma con el objetivo de liberar los presos ${ }^{91}$. En definitiva, tanto los reclusos como sus cómplices se amparaban en la oscuridad de la noche, que les garantizaba una fuga más efectiva.

\subsection{LA VIGILANCIA NOCTURNA DESDE LAS MURALLAS}

En las partidas de Alfonso X El Sabio se señala que la ciudad es todo aquel lugar que es cercado de los muros, con los arravales e con los edificios que se tienen en $e^{e l l o s}{ }^{92}$. Durante los siglos medievales no se concibe un núcleo urbano -al menos en Castilla- sin su correspondiente muralla. En el caso de las ciudades del norte de España, algunos recintos amurallados se habían levantado de nueva planta, mientras que en las ciudades del sur se conservaron las murallas de las ciudades conquistadas a los musulmanes. También es cierto que en algunos casos, el perímetro amurallado procedía de época romana o visigoda y, en estos casos, las autoridades mostraron una gran preocupación por el mantenimiento y ampliación de las murallas con motivo del crecimiento de las ciudades a fines de la Edad Media ${ }^{93}$. Cuando el cielo se oscurece en las ciudades del Reino de Castilla, la muralla adquiere una relevancia fundamental dado su carácter defensivo que impide el acceso de todo aquél que intentase entrar ilegalmente a la urbe ${ }^{94}$. Izquierdo Benito ha estudiado el sistema de vigilancia nocturno

\footnotetext{
${ }^{89}$ Partida VII, título XXIX, ley VI.

90 1596.07.14, AGS, RGS, f. 194.

91 1594.10.19, ARChVa, Reg. de Ejecutorias, 1772, f. 32.

92 Partida VII, título XXIII, ley VI.
}

93 En Toledo, los maestros de obras conocidos como "alarifes", eran nombrados por el Ayuntamiento y se encargaban de inspeccionar el estado de la muralla. Véase Ricardo IzQuierdo Benito, Un Espacio Desordenado...op. cit., pp. 20-22.

${ }^{94}$ Es menester destacar que la muralla no guardaba únicamente una función militar y defensiva pese a que sea este aspecto el que profundizaremos por vincularse a nuestro objeto de estudio. La muralla podía desempeñar una función simbólica, de manifestación del poder. Asimismo, desempeñaba una 
implementado en Toledo durante el siglo XV; a continuación recuperaremos las notas más distintivas esbozadas por el especialista puesto que el estudio del caso toledano pone de manifiesto una situación que se da de forma muy similar en el resto de las ciudades castellanas ${ }^{95}$.

Durante la noche era necesario ejercer un férreo control de las puertas principales de la muralla puesto que hemos visto que no solamente era importante evitar la entrada clandestina de individuos potencialmente sospechosos sino asimismo de mercancías sujetas al pago de un arancel que buscaba evadirse. La importancia del mantenimiento de la seguridad interior legitimaba involucrar a toda la población en el sistema defensivo desde la muralla. Los jurados de cada una de las parroquias toledanas proporcionaban los hombres que fueran necesarios para proteger la muralla. La vigilancia diurna era denominada "guardas" y solamente se solía realizar en las dos puertas (Bisagra y Cambrón) y en los dos puentes (Alcántara y San Martín). La vigilancia nocturna que se conocía como "velas" requería una mayor cantidad de personal y se ejercía a lo largo de toda la muralla, desde los cubos o torres. El sistema de vigilancia buscaba proteger los puntos más vulnerables que generalmente estaban constituidos por portillos o tramos de muralla caídos. Izquierdo Benito nos habla de dos tipos de sistema de vigilancia que solían combinarse: uno estático -cada grupo vigilaba sin moverse de un punto asignado- y otro móvil, que se caracterizaba por un grupo de hombres en constante desplazamiento a lo largo de un trayecto asignado. Los documentos relativos a los repartos de vigilancia se encuentran recogidos en el Archivo Municipal de Toledo. El primero de ellos es de abril de 1439 y de su análisis se deriva que "eran unos 57 hombres los que entonces se requerían para realizar la vigilancia nocturna del perímetro amurallado"96. La documentación conservada para el año 1461 pone de manifiesto una situación similar: mientras que vigilancia diurna es localizada en los 4 lugares tradicionales (puertas de Bisagra y del Cambrón y puentes de Alcántara y San Martín) y ocupa un número pequeño de hombres (un total de 8 personas, 2 en cada uno de los puestos), la vigilancia nocturna se ejercía a lo largo de toda la muralla ocupando un mayor contingente de individuos.

El trabajo de Izquierdo Benito nos permite inferir que en el resto de las ciudades castellanas amuralladas el sistema defensivo durante la noche era similar. Esta función protectora de la muralla- mayormente estimada en el espacio de la nocturnidadexplica la preocupación de las autoridades por su buen mantenimiento, aunque no siempre se conseguía. Sólo la realización de estudios de caso, permitirá profundizar nuestros conocimientos en el tema ${ }^{97}$.

función fiscal a partir del control de recursos económicos que se efectuaba desde las puertas. Por último, la muralla se transforma en un elemento esencial en épocas de pestes puesto que al cerrar las puertas se prohibía el ingreso de individuos portadores de enfermedades contagiosas.

${ }^{95}$ Cfr Ricardo Izquierdo Benito, "La noche de Toledo...op. cit., pp. 123-142.

${ }^{96}$ Ibidem, p. 129.

${ }^{97}$ Alfonso Franco Silva, especialista en el estudio de la nobleza castellana y de sus dominios señoriales en los siglos bajomedievales, encuentra que en tierras de Soria a fines del siglo XV, en tiempo de guerra o emergencia, los vecinos de Caracena debían participar en el servicio de vigilancia nocturna de la muralla. El autor calcula que ocho hombres bastaban para defender la fortaleza. El vecino que se negara a prestar el servicio de vigilancia nocturna, debía pagar al señor 20.000 mrs. anuales. Véase Alfonso Franco Silva, La fortuna y el poder...op. cit., pp. 217-241. Por su parte, José Manuel Escobar 
En conclusión, si la estrecha vigilancia nocturna desde la muralla no era una medida suficiente para prevenir el ingreso de individuos indeseados por el concejo, las autoridades tomaron una serie de disposiciones que ponen de manifiesto la preocupación del poder político por mantener un dominio de la noche. Con la puesta del sol, las murallas cierran sus puertas, las rondas inician sus patrullas y los habitantes de la ciudad deben evitar la circulación nocturna por las calles. Iniciado el toque de queda, la prohibición de portar armas se vuelve más severa y el requisito de traer lumbre se transforma en una obligación.

\section{ALGUNAS REFLEXIONES FINALES}

A lo largo de la presente investigación nos hemos ocupado de analizar los vínculos entre la delincuencia y la nocturnidad en las ciudades castellanas a fines de la Edad Media. El corpus documental analizado ha puesto de manifiesto que la noche era el momento más propicio para cometer diferentes tipos de delitos. Cuando el cielo se oscurecía, los asesinos, ladrones, impostores y malhechores tomaban por asalto las ciudades teniendo por cómplice a la negra noche que todo lo encubría bajo el anonimato de la oscuridad y las tinieblas.

Las autoridades citadinas se hicieron eco de las irregularidades que tenían lugar bajo el reino de la noche e inmediatamente intentaron "domesticar" la nocturnidad mediante la implementación de un conjunto de estrategias y/o herramientas que tuvieron su expresión legislativa. Los límites a la circulación nocturna, la implementación del toque de queda, la obligación de portar lumbre encendida, el control del uso de las armas, el poder otorgado a los alguaciles, las realizaciones de rondas nocturnas, las restricciones al ingreso de forasteros y el sistema de vigilancia desde la muralla fueron las medidas más importantes instrumentadas por los municipios y que ponen de manifiesto la preocupación del poder político por mantener un dominio de la noche.

Camacho ha realizado un estudio sobre las murallas cordobesas pero sin establecer un vínculo claro entre los sistemas defensivos y la nocturnidad. Véase José Manuel Escobar CAMAcho, "El recinto amurallado de la Córdoba bajomedieval", En la España Medieval, 10 (1987). 